\title{
Predictive value of systemic and local inflammation parameters in talc pleurodesis assessment
}

\author{
Petr Habal ${ }^{\mathrm{a}}$, Nedal Omrann ${ }^{\mathrm{a}}$, Karolina Jankovicova ${ }^{\mathrm{b}}$, Jan Krejsek ${ }^{\mathrm{b}}$, Jiri Mandak ${ }^{\mathrm{a}}$
}

Background. One option for the palliative treatment of recurrent malignant pleural effusion is powdered talc using thoracoscopy. This paper presents the results of selected systemic and local manifestations of the talc-induced inflammatory reaction using a videothoracoscope.

Method. A total of 114 patients with repeated malignant pleural effusion were treated at the Cardiac Surgery Clinic in Hradec Kralove from January 2010 to December 2012. Those with a life expectancy more than $\geq 3$ months were eligible for talcage surgery. The group was retrospectively divided according to treatment results into Group $A\left(N_{1}=\right.$ 98 - successful) and Group B ( $N_{2}=16$ - relapsing). The pleural effusion was quantified using ultrasound over 1 year at 3-month intervals. Systemic changes due to the inflammatory reaction (body temperature, serum leukocyte and CRP levels) were evaluated. Local indicators of inflammation included changes in the leukocyte cell population in the effusion and changes in the pleural CRP levels. The dynamics of local expression of membrane receptors TLR-2 and CD-64 on granulocyte and monocyte cell populations in the pleural effusion were also evaluated.

Results. The reaction after talcage, included a significant increase in axillary temperature and leukocyte count, $12 \mathrm{~h}$ after the procedure. The dynamics were different in the two groups. The dynamics of local inflammatory changes were an early increase in the pleural CRP levels in both groups. The time interval of local inflammatory development and duration was related to the treatment efficacy and showed a significant rise $2 \mathrm{~h}$ after talcage in Group A. In Group B the local inflammatory reaction was slower and the rise was only observed $24 \mathrm{~h}$ after talc application. A decrease in lymphocyte count and an increase in granulocyte count $2 \mathrm{~h}$ after talcage were found. After an initial drop in monocyte level, a rise occurred within $24 \mathrm{~h}$ after talcage. Changes in the expression of TLR- 2 and CD-64 receptors in relation to their cell carriers were observed depending on time after talcage.

Conclusion. The differences in the serum and pleural effusion CRP levels suggest that the surgical stress manifests itself locally in the pleural space with a lower intensity and time delay. The TLR- 2 and CD-64 receptors exhibit different behaviour depending on the type of cell membrane where they are found. The inverse relation between the granulocyte increase and TLR-2 receptor decrease in the membrane immediately after talcage is a new finding. The dynamics of TLR-2 expression on the monocytes demonstrates a direct proportion between the increasing expression of the TLR-2 receptor and increasing percent fraction of the cell carrier.

Key words: malignant pleural effusion, thoracoscopy, talc, CRP, TLR-2, CD-64

Received: October 14, 2013; Accepted with revision: June 12, 2014; Available online: July 18, 2014 http://dx.doi.org/10.5507/bp.2014.038

${ }^{a}$ Department of Cardiac Surgery, Faculty of Medicine in Hradec Kralove, Charles University in Prague and University Hospital in Hradec Kralove, Czech Republic

${ }^{b}$ Department of Clinical Immunology and Allergy, Faculty of Medicine in Hradec Kralove, Charles University in Prague and University Hospital in Hradec Kralove

Corresponding author: Jiri Mandak, e-mail:jiri.mandak@centrum.cz

\section{INTRODUCTION}

Malignant pleural exudate is formed in a pathologically modified space between the sheaths of the parietal and visceral pleura. The worldwide annual incidence of pleural effusion is $0.06 \%$ (ref. $^{1,2}$ ). No binding rules can be specified for the diagnostic procedure, nor can a template of unified therapeutic guidelines be set up for the treatment of pleural effusion, which has multi-factorial etiology.

It is possible to assess the effusion type in relation to the basic malignant disease based on the results of indirect diagnostic methods ${ }^{3}$. Evidence of malignant pleural involvement can be derived from cytological investigation of the pleural fluid or more precisely, from histological investigation of tumours of parietal or visceral pleura ${ }^{4,5}$.

Recurrent malignant pleural effusion presents a serious complication that can induce metabolic deterioration, increase the rate of infectious lung complications and worsen the quality of a patient's life. One efficient option for palliative treatment of recurrent malignant pleural effusion is pleurodesis.

Post-inflammatory induced pleurodesis using a chemical substance prevents the accumulation of pleural fluid. The first reports of chemical pleurodesis date back to the early $20^{\text {th }}$ century ${ }^{6}$. However, to date, we still lack a safe, efficient and reasonably priced substance for pleurodesis. Substances that had been used for pleurodesis include tet- 
racycline type antibiotics, antimalarials, cytostatics, and radioactive gold colloids ${ }^{7,8}$. The use of immunomodulatory substances, interferons and inflammation mediators such as TGF- $\beta$ (transforming growth factor beta) has been described $^{9}$. The application of hyperosmolar $50 \%$ glucose solution was tested for this purpose as well. Instillation of autologous blood into the pleural cavity at $1 \mathrm{ml} / \mathrm{kg}$ of total body weight seemed to be a promising option ${ }^{10}$. Suspensions of killed strains of Corynebacterium parvum were applied in the 1970s. However, due to the increased rates of infectious complications and anaphylactic reactions, its use was prohibited ${ }^{11}$.

Talc application using the video-assisted thoracoscopic (VTS) method, is an efficient option for the palliative treatment of relapsing malignant pleural effusion ${ }^{12}$. A number of studies have provided sufficient evidence that talc in its powder form is still the most efficient substance forinducing chemical plurodesis ${ }^{13,14}$. (The first to use thoracoendoscopy was Hans Christian Jacobeus, professor of internal medicine in Sweden in 1910) (ref. ${ }^{15}$ ). The safety of this procedure is documented by the low mortality rate which is $0.5 \%$ (ref. $^{16}$ ).

The intrapleural administration of talc, provokes an inflammatory response characterized by an increase in the production of Interleukin-8 (IL-8) (ref. ${ }^{17}$ ). It has been suggested that IL- 8 is involved in the chemotaxis of neutrophils and monocytes into the pleural cavity ${ }^{18}$. Talc particles activate the mesothelium of both the visceral and parietal

Pleurae resulting the production of a fibrinous exudate that brings both surfaces together. In addition mesothelial cells can contribute to driving the pleurodesis process. Stabilization of this fibrin network and increased levels of basic fibroblast growth factor, result in the recruitment and proliferation of fibroblasts ${ }^{19}$.

An increased incidence of complications in patients with malignant pleural effusion who undergo thoracoscopy is mostly associated with the basic diagnosis itself rather than the surgical technique used ${ }^{20}$.

As mentioned above, pleurodesis is an inflammatoryinduced process. Thus, it would be useful to examine the intensity of the inflammation activity in the pleural cavity, which may in turn serve as a predictor of the efficacy of the pleurodesis.

Manifestation of this therapeutically induced aseptic inflammatory reaction, can be divided into systemic and local. The parameters of the systemic inflammatory reaction can be measured and quantified by body temperature, leukocyte level, C - reactive protein level and erythrocyte sedimentation rate. However, because of their high non-specificity, none of them can be used for quantifying the ongoing inflammatory activity, and hence, they have a poor predictive value regarding the success of the pleurodesis. Thus, the effort is to find a specific indicator for the intensity of the induced inflammatory activity in the pleural cavity

A rise in body temperature is the first defensive mechanism. It is induced by endogenous low-molecular-weight pyrogens. They are formed by activated monocytes, macrophages, lymphocytes and neutrophilic leukocytes. They are released by the effect of microbial components and products of phagocytosis. The first evidence for the use of temperature for diagnosis dates back to the early $19^{\text {th }}$ century ${ }^{21}$.

Mediators, histamine being the most important one, are released from mast cells and basophils by activation of the complement system. Together with bradykinin, histamine is a vasodilator that act on free nerve ends and causing pain ${ }^{22}$. Pain is subjective but it can be quantified using the Visual Analog Scale (VAS) after Scott-Huskinsson ${ }^{23}$.

Monitoring of blood leukocytes has a higher explanatory power as regards the development of the inflammation. At the beginning of the reaction, leukocytes decrease due to their adherence to vascular endothelium. This depletion is compensated by their hyperproduction in bone marrow $^{24}$.

The C-reactive protein (CRP), a pentameric protein produced by the liver, is used to monitor the dynamics of inflammation. CRP was described by Tillett and Francis in 1930 (ref. ${ }^{25}$ ). It has the capacity to precipitate pneumococcal C-polysaccharide ${ }^{26}$. CRP can recognize foreign bacteria as well as the body's own damaged cells. A receptor for CRP, the Fc receptor for Immunoglobulin $G$, is present on macrophages ${ }^{27}$.

Its physiological value is $0-10 \mathrm{~g} / \mathrm{L}$, typically higher in women than in men, and increasing with increasing age. Its concentration increases 6-9 $\mathrm{h}$ after an insult, to attain its peak level the $3^{\text {rd }}$ day. CRP is the protein that "reacts" fastest to an inflammatory stimulus. The values depend on the stimulating factor of inflammation and on its intensity. Its formation is induced by interleukin- 6 , produced by macrophages at the site of inflammation. The proinflammatory interleukin-1 and tumour necrotizing factor alpha have less effect on the formation of CRP ( ref. $^{28}$ ).

The CRP levels correlate with BMI and central obesity indicators. This is due to hyperproduction of IL-6 in adipocytes of the visceral fat tissue which is transported via vena portae to the site of CRP formation - the liver. Genetic factors play a role in CRP variability within the population $^{29}$.

As regards cell receptors, we focused on evaluation of local expression of the membrane receptors TLR-2 and CD-64 on granulocyte and monocyte populations.

\section{MATERIAL AND METHODOLOGY}

A total of 114 patients with recurrent malignant pleural effusion were treated at the Cardiac Surgery Clinic, Faculty of Medicine, Charles University in Hradec Kralove from January 2010 to December 2012. Patients whose life expectancy exceeded 3 months were eligible for surgery. The patients were retrospectively divided by treatment results into Group $\mathrm{A}\left(\mathrm{N}_{\mathrm{A}}=98\right.$ - non relapsing $)$ and Group $B\left(N_{B}=16\right.$ - relapsing $)$. Since effusion volume was the only objectively measurable quantity, this parameter was selected for the assessment of the effect of the talc. Ultrasound was used. This parameter was measured over 1 year at 3-month intervals. Systemic changes due to the inflammatory reaction (body temperature, serum 
leukocyte and CRP levels) were evaluated as well. Local indicators of inflammation that were evaluated included changes in leukocyte count in the pleural effusion and changes in the pleural CRP levels. The dynamics of changes in the expression of the membrane receptors TLR-2 and CD-64 on granulocytes and monocytes in the pleural effusion were monitored.

(The life expectancy due to the malignant diagnosis was up to 12 months).

Talc was applied thoracoscopically at the recommended dose of $5 \mathrm{~g}$ (ref. $\left.{ }^{30}\right)$. The rules for fractionated evacuation of the pleural effusion using portions up to $750 \mathrm{~mL}$ were adhered to in order to avoid formation of a re-expansive pulmonary edema (RPE). The fluid evacuation procedure and observation of the pleural cavity were followed by biopsy of the parietal pleura. Four hours after the procedure, the chest tube was connected to gravity drainage only. Active suction with a controlled vacuum level of $-20 \mathrm{~cm} \mathrm{H}_{2} \mathrm{O}$ was applied during the next $4 \mathrm{~h}$. The chest tube was removed when the volume of waste was lower than $150 \mathrm{~mL}$ during $24 \mathrm{~h}$.

A volume of $5 \mathrm{~mL}$ of the pleural effusion was collected in a test tube with heparin by means of a BD Vacutainer ${ }^{\circledR}$ (BD Becton, Dickinson and Company, USA) with commercially ensured defined heparinization.

The sample was centrifuged, and flow cytometry was used to determine the fractions of leukocyte subpopulations - lymphocytes, granulocytes and monocytes. The cell immunity parameters were assessed by immunofluorescence analysis on an FACS Calibur flow cytometry system (Becton Dickinson, San Jose, USA) based on cell size and morphology.

The effusion volume was determined by the ultrasound method on a Toshiba Xario ${ }^{\circledR}$ instrument (Toshiba Medical Systems, Sweden) using a conventional 2-5 MHz probe.

\section{Statistical analysis}

Flow cytometry data were analysed using FlowJo software (Tree Star, USA). Clinical data, flow cytometry results and ELISA results were statistically analysed using Med Calc statistical software. Comparison among pleural effusion collection in the three intervals was assessed using paired t-test or Wilcoxon test according to the normality of the data. Differences between groups were tested using t-tests or Mann-Whitney test. Categorical data were tested by the Fisher's exact test. Statistical significance was set at $P=0.05$.

The study protocol was approved by the Ethics Committee of the University Hospital in Hradec Kralove and an informed consent was obtained from all participants.

\section{RESULTS}

The cohort consisted of 114 patients with etiologically different malignant effusion, of whom 61 (53.5\%) were men and $53(46.5 \%)$ were women. In 98 (86\%) patients (Group A) the treatment was efficient and no postoperative chest paracentesis was necessary, whereas in 16 (14\%) patients (Group B) the treatment failed. Mean patient age was $63.6 \pm 3.2$ years in Group A and $67.8 \pm 2.4$ in Group B. The basic data are included in Table 1. The mean duration of the surgery was $44 \pm 12$ minutes, the mean time of chest drainage was $5 \pm 2$ days. The mean length of hospitalization was $7 \pm 2$ days. One death occured due to global respiratory insufficiency $28 \mathrm{~h}$ after the surgery as a result of the development of a re-expansive pulmonary edema (RPE), the other death was due to a massive pulmonary embolism of the left lung wing $34 \mathrm{~h}$ after the surgery.

The intensity of the overall inflammatory reaction was quantified by monitoring body temperature, serum leukocyte level, and CRP serum level.

Table 1. Basic diagnoses $(n=114)$.

\begin{tabular}{lccc}
\hline & Group A* & Group B* & $P$ \\
\hline Age (year) & $63.6 \pm 3.2$ & $67.8 \pm 2.4$ & $<0.05$ \\
BMI (kg.m ${ }^{-2}$ ) & $27(23-29)$ & $26(24-30)$ & n.s. \\
thoracoscore** & $5.4(2.7-8.2)$ & $6.9(5.2-7.9)$ & $<0.05$ \\
Carcinoma of lungs n (\%) & $29(29.6 \%)$ & $2(14.3 \%)$ & $<0.001$ \\
Malignant mesothelioma n (\%) & $25(25.6 \%)$ & $8(50 \%)$ & $<0.001$ \\
Lymphoma of lungs n (\%) & $2(5.1 \%)$ & $6(42.8 \%)$ & $<0.001$ \\
Metastases n (\%) & $39(39.8 \%)$ & $-2(33.3 \%)$ & $<0.001$ \\
- breast n (\%) & $-19(48 \%)$ & $-4(66.6 \%)$ & $<0.001$ \\
- ovary n (\%) & $-12(30.8 \%)$ & 0 & $<0.01$ \\
- GIT n (\%) & $-4(10.3 \%)$ & 0 & $<0.001$ \\
- Grawitz n (\%) & $-2(5.1 \%)$ & $16(14 \%)$ & $<0.001$ \\
\hline$\Sigma$ n (\%) & $98(86 \%)$ & & $<0.001$ \\
\hline
\end{tabular}

BMI - Body mass index,

*median (minimum - maximum)

A - group without exudate relapsing, B - group with exudate relapsing

**Falcoz PE et al. The Thoracic Surgery Scoring System (Thoracoscore): Risk model for in hospital death in 15,183 patients requiring thoracic surgery. J Thorac Cardiovasc Surg 2007;133:325-32. 


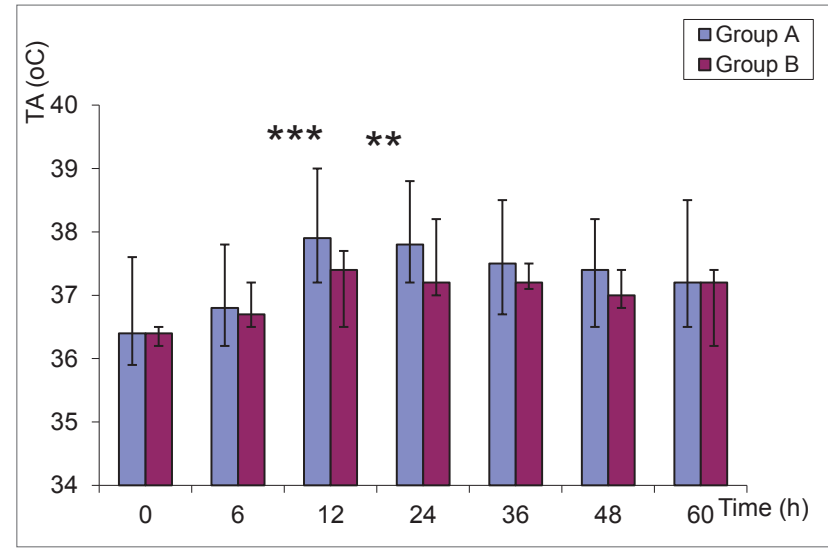

Fig. 1. Body temperature dynamics (in ${ }^{\circ} \mathrm{C}-$ degrees centigrade) in Groups A and B.

$* * P<0.01,{ }^{*} * * P<0.001$

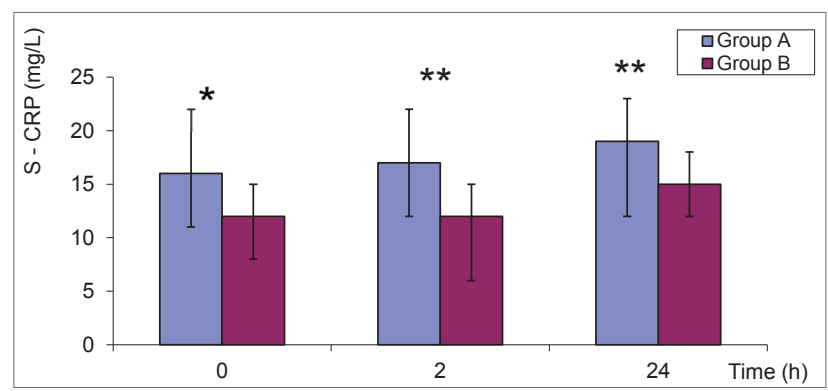

Fig. 3. Serum CRP level dynamics in Groups A and B. $\mathrm{S}$ - CRP - serum CRP levels $(\mathrm{mg} / \mathrm{L}),{ }^{*} P<0.05, * * P<0.01$

A significant difference in axillary temperature increase between Groups A and B occurred $6 \mathrm{~h}$ after administration of talc, and a statistically significant difference between Groups A and B was found within the period of 12 to $24 \mathrm{~h}$ after talc administration $\left(P_{12}=0.0003, P_{24}\right.$ $=0.0021$ ), Fig. 1 . An increase in serum leukocyte level occurred in $12 \mathrm{~h}$ in both groups, and a statistically no significant difference between Groups A and B appeared 24 hours after talc administration $\left(P_{24}=0.071\right)$. The maximum leukocytes level was found 36 to $60 \mathrm{~h}$ after the talc

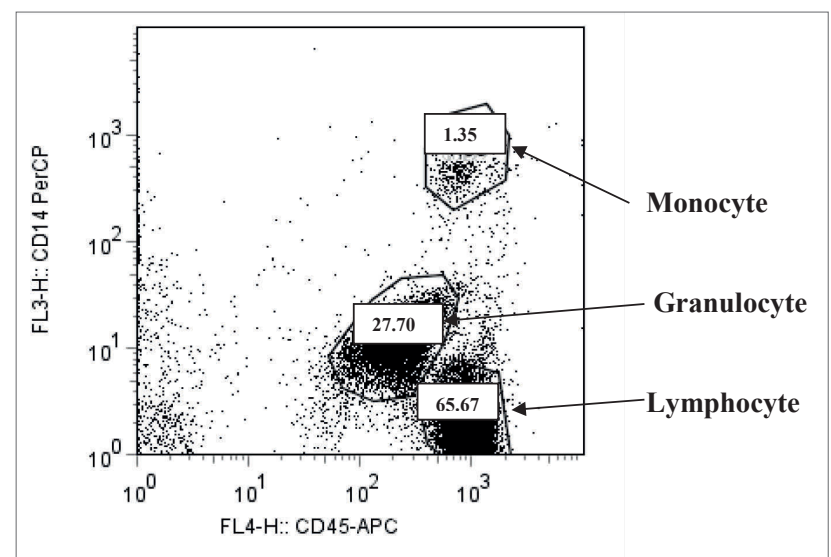

Fig. 5. Relative fraction of leukocytes in effusion (by flow cytometry) prior to talcage.

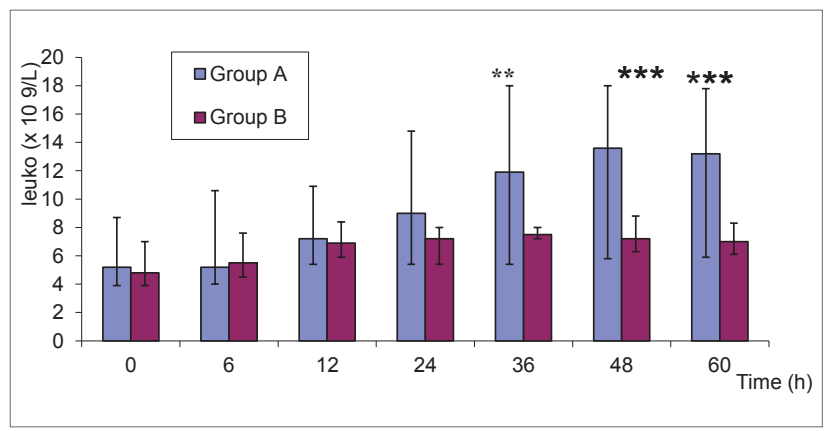

Fig. 2. Blood leukocyte level dynamics in Groups A and B. $* * P<0.01, * * * P<0.001$

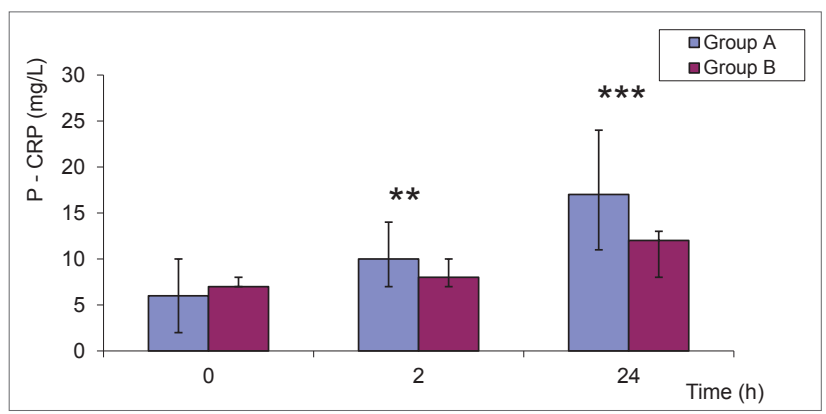

Fig. 4. Pleural fluid CRP level dynamics in Groups A and B. $\mathrm{P}$ - pleural effusion CRP levels $(\mathrm{mg} / \mathrm{L}),{ }^{*} P<0.01, * * * P<0.001$

instillation $\left(P_{36}=0.0023, P_{48}=0.00012, P_{60}=0.00014\right)$, Fig. 2. A significant elevation in serum CRP level in Group A was evident in the $1^{\text {st }}$ blood sample obtained after the initiation of VTS procedure and prior to talc application and this trend was observed during the entire monitoring period $\left(P_{0}=0.034, P_{2}=0.0017, P_{24}=0.0015\right)$, Fig. 3 . The baseline serum CRP levels were identical in both groups $(P=0.062)$.

Manifestation of the local inflammatory process in the pleural cavity was assessed by the changes in CRP levels in the pleural fluid. Elevated pleural fluid CRP levels of no statistical significance were found in Group B prior to

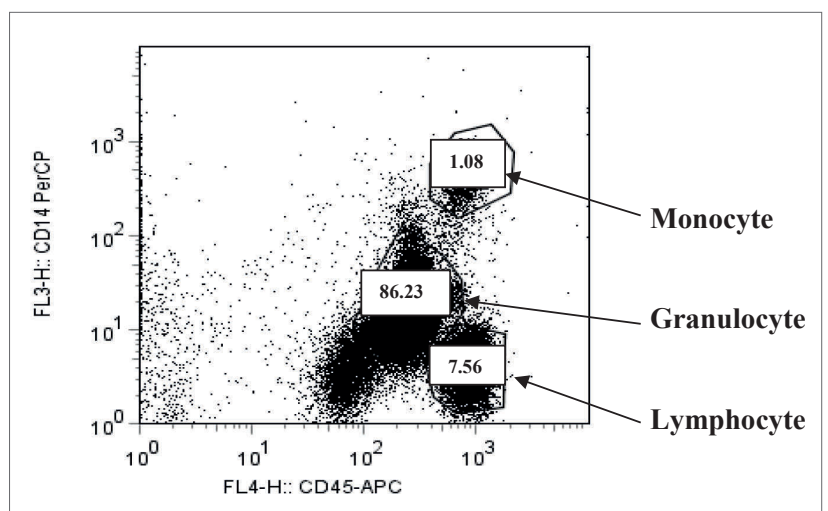

Fig. 6. Relative fraction of leukocytes in effusion (by flow cytometry) $2 \mathrm{~h}$ after talcage. 


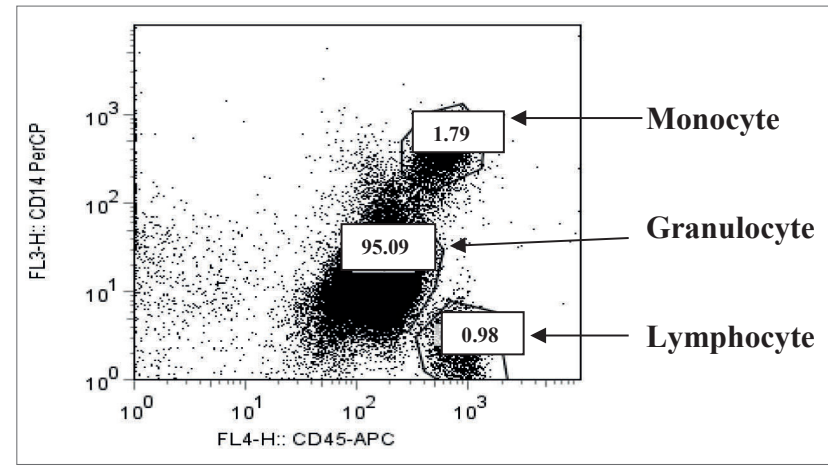

Fig. 7. Relative fraction of leukocytes in effusion (by flow cytometry) $24 \mathrm{~h}$ after talcage.

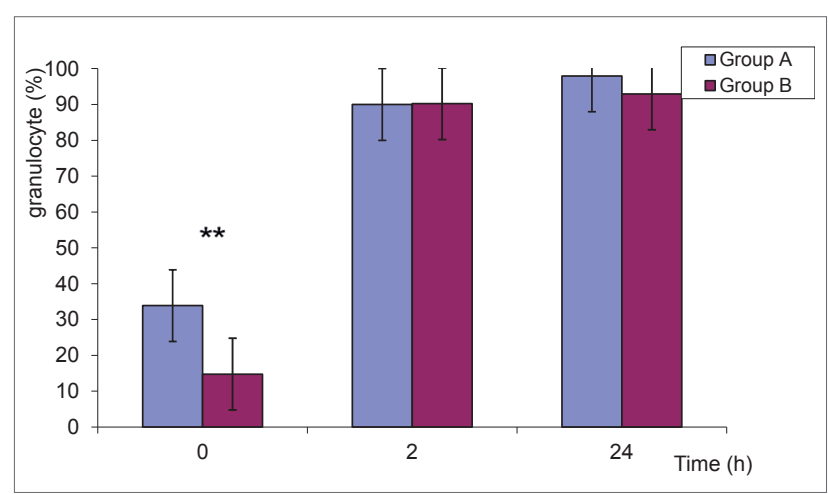

Fig. 9. Relative granulocyte level dynamics in Groups A and B. $* * P<0.01$

talc powdering. However, a statistically significant difference in pleural fluid CRP levels between Group A and B was observed $2 \mathrm{~h}$ after talc instillation, and this difference continued to increase during the monitoring period $\left(P_{2}=\right.$ $\left.0.0074, P_{24}=0.00034\right)$, Fig. 4 .

A sharp drop of the lymphocyte population and a growth of the granulocyte population were observed after the talcage. Monocytes exhibited minimal change dynamics, Fig. 5-7.

No statistically significant difference between Groups $\mathrm{A}$ and $\mathrm{B}$ was found in the decrease of percent fractions

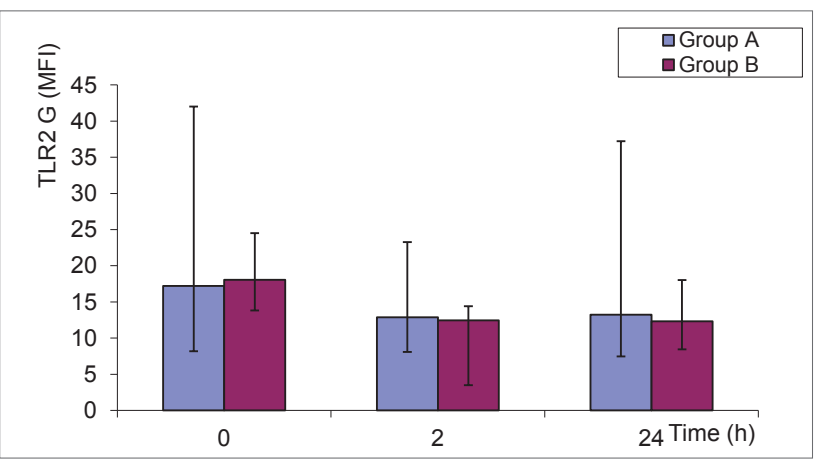

Fig. 11. TLR-2 level dynamics on granulocytes in Groups A and $\mathrm{B}$.

MFI - mean fluorescence intensity

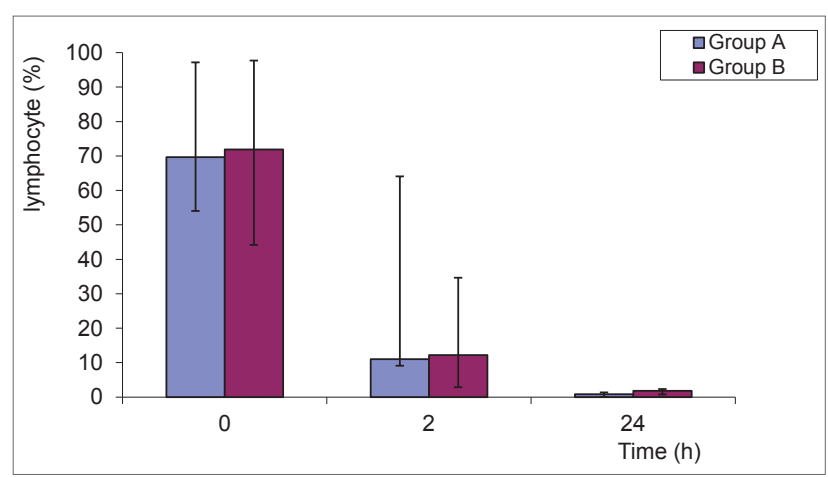

Fig. 8. Relative lymphocyte level dynamics in Groups A and B.

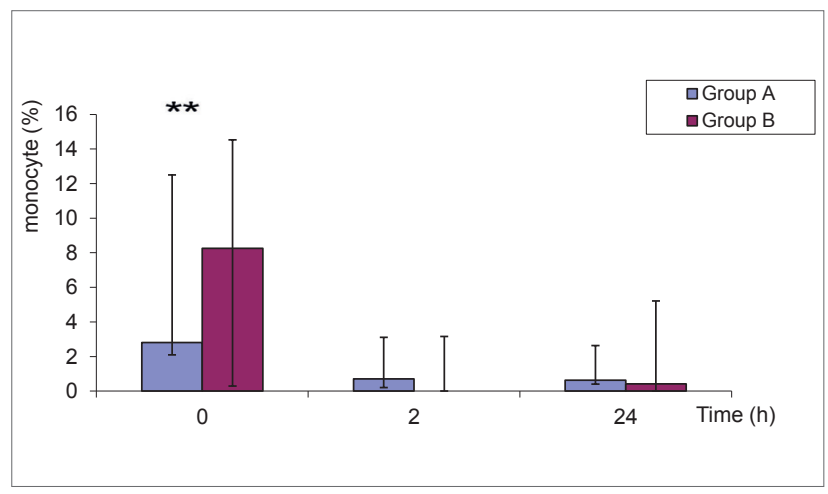

Fig. 10. Relative monocyte level dynamics in Groups A and B. $* * P<0.01$

of lymphocytes, Fig. 8, where as a statistically significant difference was found in the granulocyte fractions prior to talcage $\left(P_{0}=0.0016\right)$, Fig. 9. A pronounced increase occurred in both groups, with no significant difference between them. As regards the monocyte subpopulation, there was a statistically significant difference between the baseline levels prior to talcage $\left(P_{0}=0.0019\right)$. A decrease without statistical significance between Groups A and B followed, Fig. 10.

Local expression of membrane receptors TLR-2 and CD-64 on granulocyte and monocyte cell populations and

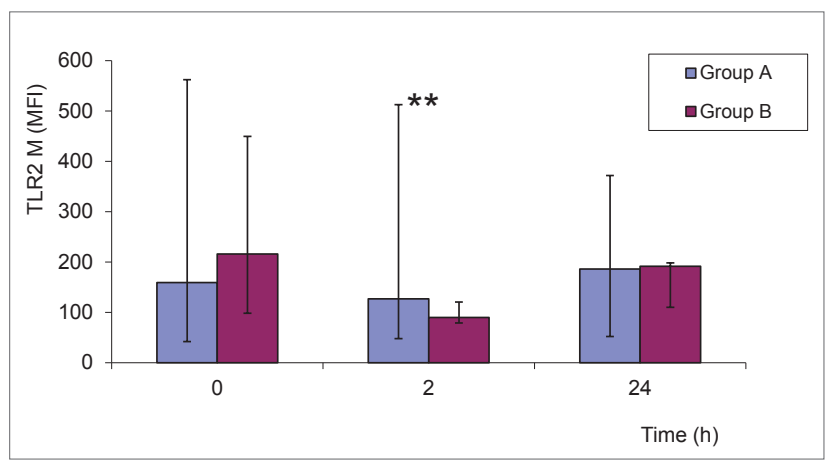

Fig. 12. TLR-2 level dynamics on monocytes in Groups A and $\mathrm{B}$.

$* * P<0.01, \mathrm{MFI}-$ mean fluorescence intensity 


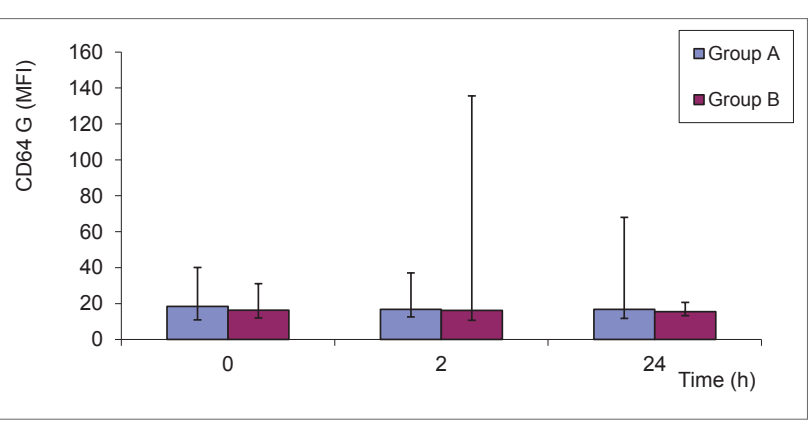

Fig. 13. CD-64 level dynamics on granulocytes in Groups A and $\mathrm{B}$.

MFI - mean fluorescence intensity

its dynamics were evaluated. No statistically significant differences between the two groups were found in the surface expression of the TLR-2 receptor on granulocytes, Fig. 11, where a statistically significant difference was found in its surface expression on monocytes $2 \mathrm{~h}$ after the application of talc $\left(P_{2}=0.00078\right)$, Fig. 12. No significant difference between Groups A and B was found for expression of CD-64 on granulocytes, Fig. 13, where a significant increase in the expression of this antigen on monocytes was found in Group B $24 \mathrm{~h}$ after the application of talc $\left(P_{24}=0.00042\right)$, Fig. 14 .

\section{DISCUSSION}

Repeated formation of an effusion disturbs metabolic and mineral homeostasis and induces the terminal state of cancer cachexia. Dyspnea on exertion and later dyspnoea at rest are the first symptoms associated with an effusion accumulation in the pleural cavity. The increase in the amount of the pleural effusion causes compression of the lung parenchyma with a subsequent development of lung atalectasis, which may contribute to further worsening of the patient's symptoms. The patient is at high risk of pneumonia development in the territory of non-ventilated lung parenchyma. This risk however is higher in the case of patients with malignancies due to their previous chemotherapy/radiotherapy.

The probability of the infection propagation into the pleural space and formation of thoracic empyema increases with the increasing number of thoracic paracentesis procedures. Its treatment is usually complicated by fibrothorax, which requires a hazardous decortication of the affected lung parenchyma. Immobilization, malignant tumours and previous cancer therapy are among the highest-risk factors for fatal pulmonary embolism ${ }^{31}$.

The cohort of 114 patients was divided into 2 groups according to treatment results. Group A (98 patients) included patients in whom the treatment was successful whereas Group B (16 patients) included patients who had to undergo repeated thoracic paracentesis or drainage.

There were no statistically significant differences for basic demographic parameters except for age. The 2 groups had different baseline parameters indicating the patients' physical condition and polymorbidity, which

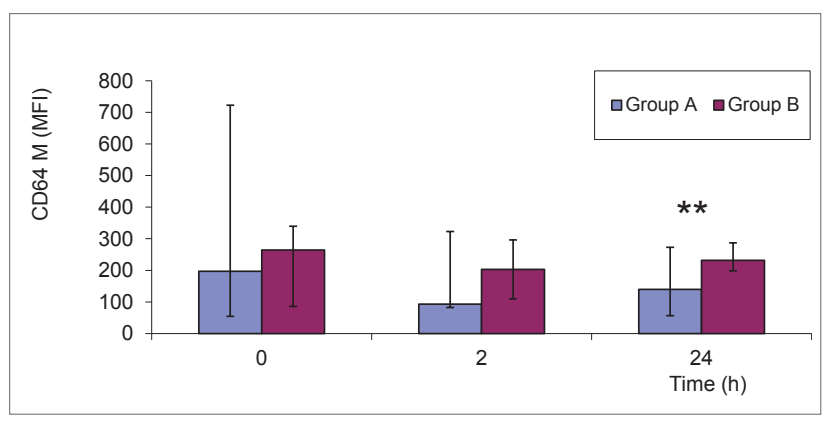

Fig. 14. CD-64 level dynamics on monocytes in Groups A and B.

$* * P<0.01$, MFI - mean fluorescence intensity

are best expressed comprehensively by the thoracoscore index.

The diagnosis of malignant disease had no effect on the therapy outcome for two reasons. The first reason was the correct indication of patients for surgical intervention during malignant disease remission. The second reason was the identical mechanism of pleural effusion formation, which is pleural fluid hyperproduction and hyporesorption induced by aseptic pleuritis and blockage of the pleural stomata by large cancer cells, respectively.

The spectrum of concomitant diseases had no effect on the treatment outcome, either. Surgery induces operational trauma with activation of the blood coagulation and fibrinolysis system and triggers a cascade of the body's inflammatory response ${ }^{32}$. This results in repair and healing of the damaged tissue ${ }^{33}$. The systemic inflammatory response syndrome (SIRS) develops if the reaction is inadequate. A vigorous inflammatory reaction can stimulate acceleration of the latent form of atherosclerosis ${ }^{34}$. Cases of increased incidence of heart attacks due to persisting elevated leukocytes have also been reported ${ }^{35}$. Changes in the immune system reaction can be detected after surgical procedures despite efforts to eliminate the operational trauma. These efforts lead to suppression of the cell type immune reaction with subsequent lymphopenia ${ }^{32}$. The intensity of the reaction depends on the nature of the procedure and on the amount of foreign material used during surgery. This is why activation of the immune system is significant in cardiac surgery when the extracorporeal circulation is used ${ }^{36}$.

In patients undergoing pleurodesis, the aim is to trigger the inflammatory chain reaction and to increase its intensity using talc as an inflammation-inducing substance. The intensity of the induced inflammatory reaction can be measured and quantified, although the measured systemic changes are highly non-specific. It is difficult to discriminate between the effect of the surgical stress and the effect of the foreign substance on the ongoing systemic inflammatory reaction. In our cohort, the application of a unified surgical and anaesthetic technique may have reduced the surgical stress.

Non-specific inflammatory reactions, such as rise in axillary temperature and leukocyte level increase, were observed $12 \mathrm{~h}$ after the surgical procedure. These changes are concordant with the generally recognized theory of 
inflammation described by Ilya Il'ich Mechnikov in 1903 $\left(\right.$ ref. $\left.{ }^{37}\right)$.

The operational/anaesthesiological stress is immediately translated and mirrored by the immune response, as demonstrated by the increased serum CRP levels even prior to talcage. Group A had a faster inflammatory response than Group B, which indicates a better immune system predisposition to react to external stimuli.

Since this study was focussed on the detection and evaluation of early changes in inflammatory indicators, maximum CRP levels were not recorded since it is well known that the peak serum CRP levels during a bacterial infection are registered up to 3 days after the triggering moment $^{38}$. In our pilot study, maximum serum concentrations were attained between $36-48 \mathrm{~h}$ after talc application ${ }^{39}$.

The dynamics of the local inflammatory changes are indicated by the early pleural CRP level increase observed in the whole sample as well as in the comparison of the two groups as early as $2 \mathrm{~h}$ after talcage. The local inflammatory reaction registered as a significant increase in the CRP level $2 \mathrm{~h}$ after talcage and a persisting trend throughout the monitoring period in Group A. In Group B, the reaction was slower and the increase of inflammatory indicators lasted over $24 \mathrm{~h}$. This may be suggestive of a different state of the immune system in each group.

The different changes in serum and pleural CRP levels indicate that the surgical stress contributed minimally to the local intrapleural inflammatory changes and with a delay.

Changes in the inflammatory cell response occurred in the interpleural space. The relative lymphocyte fraction decreased as early as $2 \mathrm{~h}$ after talcage and granulocytes increased significantly. The relative monocyte fraction decreased $2 \mathrm{~h}$ after talcage to start increasing again in $24 \mathrm{~h}$. These findings are confirmed by other authors ${ }^{40}$. In our previous study, different levels of local soluble receptors, reflecting the local inflammatory activity in the pleural effusion, were found between the group of patients with successful and unsuccessful pleurodesis ${ }^{41,42}$.

To our knowledge, no study has assessed the direct effect of pleural talcage on the dynamic of changes in cell immunity in the pleural space. We were unable to clearly demonstrate statistically significant differences in the relative fractions of various immune cell elements between Groups A and B due to the different number of patients in each group.

External stimuli of the immune system induce signals whose identification is mediated by toll-like receptors (TLR). So far, the changes in these receptors expression in response to inflammatory stimuli have been known from experimental studies only ${ }^{43}$.

It was demonstrated on the patient cohort examined that TLR-2 receptor expression on granulocytes drops rapidly immediately after the surgery and talc application. An inverse proportionality was found between the increase in relative granulocyte fraction and decrease in TLR-2 receptor level on the membrane immediately after talcage.

The dynamic of TLR-2 expression on monocytes dem- onstrates a direct relation between the increase in TLR-2 receptor expression and increasing percent fraction of the cell carrier.

The dynamics of expression of the activation CD-64 molecule on granulocytes, which is increased by proinflammatory effects, demonstrated substantial differences between the groups as early as $2 \mathrm{~h}$ after talcage. CD-64 expression on monocytes was an order of magnitude higher than expression on granulocytes, although the change in the percent fraction of monocytes within the cell reaction type was minimal.

The VTS method of talcage was safe in the selected group of patients. The most frequent complication included various forms of respiratory insufficiency. RPE, with a fatal outcome, was a rare complication. RPE (with incidence ranging from 0 to $14 \%$ ) occurs after sudden reexpansion of a long collapsed lung parenchyma and has a mortality rate of up to $20 \%$ (ref. ${ }^{44}$ ).

Pinault described the first report of this complication in 1853 after providing thoracocentesis ${ }^{45}$. The pathophysiological mechanisms of RPE development have not been recognized in detail. Long vasoconstriction after hypoxia in the collapsed lung wing induces ischemic damage of the lung parenchyma at the cell level.

Rapid re-expansion of the lung wing causes a re-perfusion injury by the released oxygen radicals with damage of the alveolo-capillary barrier and development of the capillary leak syndrome. Activation of monocytes, macrophages and neutrophils causes damage to the microcapillaries and the alveolo-capillary barrier in the pulmonary microcirculation. This can explain the involvement of non-collapsed pulmonary parenchyma as well as of some other parenchymatous organs ${ }^{46}$.

In our sample, RPE induced acute respiratory failure in one patient, which could not be managed by routine methods, including the use of extracorporeal oxygenator, considering the diagnosis of the malignant disease.

\section{CONCLUSION}

Palliatively induced pleurodesis is a result of the inflammatory reaction in both pleural membranes. A successful development of the reaction depends on the overall biological condition and metabolic activity of the organism. The establishment of conditions for a sufficiently long contact of the two pleural membranes plays an important role. The effect of the therapy was unaffected by the type of cancer involving the pleura.

The significant proinflammatory trigger caused by the operational stress was evident. The different changes in the serum and pleural effusion CRP levels showed that the inflammatory activity is expressed locally in low intensity and with a delay.

The TLR-2 and CD-64 receptors exhibit different behaviour dependingon type of cell membrane where they are found.

There was no correlation between the type of malignant affection and the outcome of the chemical pleurodesis. 
So far, no study has assessed the direct effect of pleural talcage on the dynamics of change of cell immunity in the pleural space. For clinical practice, examination of CD-64 in routine analysis using the ELISA method on samples of pleural fluid could be done. The fee for this examination is around 20 Euros.

\section{ACKNOWLEDGEMENTS}

Supported by the programme PRVOUK P37/4 and the MH CZ-DRO (UHHK, 00179906).

Author contributions: PH, JM: manuscript writing; NO: literature search; KJ, JK: contribution of cytometry and immunofluorescence analysis.

Conflict of interest statement: The authors state that there are no conflicts of interest regarding the publication of this article.

\section{REFERENCES}

1. Marel M, Zrustova M, Stastny B. The incidence of pleural effusion in a well-defined region. Epidemiologic study in central Bohemia. Chest 1993;104:1486-9.

2. Bennett R, Maskell N. Management of malignant pleural effusions. Curr Opin Pulm Med 2005;11:296-300.

3. Neville E, Antunes G, Duffy J. On behalf of the BTS Pleural Disease Group a subgroup of the BTS Standards of Care Committee. BTS guidelines for the management of malignit pleural effusions. Thorax 2003;58(2):1129-38.

4. Scott EM, Marshall TJ, Flower CD. Diffuse pleural thickening: percutaneous CT-guided cutting needle biopsy. Radiology 1995;194:867-70.

5. Screaton NJ, Flower Ch. Percutaneous needle biopsy of the pleura interventional. Chest Radiology 2000;38:293-301.

6. Bouros D, Froudarakis M, Siafakas NM. Pleurodesis: everything flows. Chest 2000;118: 577-9.

7. Markman M, Clary S, King ME. Cisplatin and cytarabine adminis tered as treatment of malignant pleural effusions. Med Pediatr Oncol1985;13:191-3.

8. Walker-Renard PB, Vaugham LM, Sahn SA. Chemical pleurodesis for malignant pleural effusions. Ann Intern Med 1994;120:56-64.

9. Rosso R, Rimoidi R, Salvami F. Intrapleural natural beta interferon in the treatment of malignant pleural effusions. Oncology1988;45:253-6.

10. Randal E, Mitchem L, Herndon M, Fiorell a. Pleurodesis by autologous blood, doxycycline and talc in a rabbit model. Ann Thorac Surg1999;67:917-21.

11. Webb HE, Osten SW. Treatment of malignant ascites and pleural effusions with Corynebacterium parvum. Br Med J1978;1:338-40.

12. de Campos J, Vargas FS, Werebe E. Thoracoscopic talc poudrage: a 15-year experience. Chest 2001;119:801-6.

13. Colt HG, Russack A, Chiu Y. A comparison of thoracoscopic talc insufflation, slurry, and mechanical abrasion pleurodesis. Chest 1997; $111(2): 442-8$

14. Stefani A, Natali P, Casal C. Morandi U. Talc poudrage versus talc slurry in thetreatment of malignant pleural effusion. A prospective comparative study. Eur J Cardiothorac Surg 2006;30(6):827-32.

15. Jacobeus HC. The practical importance of thoracoscopy in Surgery of the chest. Surg Gynecol Obstet 1922;34:289-96.

16. Stammberger U, Steinacher C, Hillinger S. Early and long term complains following videoassisted thoracoscopic surgery. Cardiothorac Surg 2000;18:7-11.

17. Van den Heuvel MM, Smith JM, Barbierato SB et al. Talc-induced infammation in the pleural cavity. Eur Respir J 1998;12:1449-23.

18. Antony VB, Godbey SW, Kunkel SI et al. Recriument of inflammatory cells to the pleura space. Chemotactic cytokines, IL- 8 and monocyte chemotactic peptide-1 in human pleural fluids. J Immunol 1993;151:7216-23.
19. Antony VB, Kamal MA, Godbey SW. Talc induced pleurodesis: role of a fibroblast growth factor (bFGF). Eur Respir J 1997;10:2411-8.

20. Yim AP, Chung SS, Lee TW. Thoracoscopic management of malignit pleural effusions. Chest1996;109:1234-8.

21. Kirby RR, Civetta JM, Tailor RW. Problems in anaesthesia Hypothermia/Hyperthermia. Critical Care Medicine 1994;8:1-10.

22. Hornick P, Georgie A. Blood contact activation: pathophysiological effects and terapeutic approches. Perfusion 1996;11:3-19.

23. Sofaer B. Bolest - príručka pro zdravotní sestry. 1. vyd. Praha: Grada 1997; 107 s. ISBN80-7013-386-394.

24. Christensen R, Bradley PP, Rothstein G. The leukocyte left shift in clinical and experimental neonatal sepsis. J Pediatr 1981;98:101s.

25. Volanakis JE. Human C-reactive protein:expression, structure and function. Mol Immunol 2001;38:189-97.

26. Tillet WS, Francis T. Serological reactions in pneumonia with non protein somatic fraction of pneumococcus. J Exp Med 1930;2:561s.

27. Bharadwaj D, Stein MP, Volze M. The major receptor for C-reactive protein on leukocyte Fc receptor II. J Exp Med 1999;190:585-90.

28. Castell JV, Gomez-Lechon MJ, David M. Interleukin-6 is the major regulator of acute phase protein synthesis in adult human hepatocytes. FEBS Lett1989;242:237-9.

29. Basso F, Lowe DO, Rumley A. Interleukin-6 174G polymorphism and risk of coronary heart disease in West of Scotland Coronary Prevention Study (WOSCOPS). Arterioscler Tromb BASF Biol 2002;22:599-604

30. Cau P, Astoul P. Distribution of calibrated talc after intrapleural administration: an experimental study in rats. Chest 2002;122:1737-41.

31. Widimsky J, Maly J. Doporučení diagnostiky a léčby plicní embolie. Cor\&Vasa1998; 40:139-54.

32. Shimaoka M, Hosothubo K, Sugimoto $M$. The influence of surgical stress on t cells? Enhancement of early phase lymfocyte activation. Anesth Analg 1998;87:1431-5.

33. De Longu G, Moretti S, Antonucci A. Apoptosis and surgical trauma. Arch Surg 2000; 135:1141-7.

34. Krejsek J. Ateroskleróza - důsledek dlouhodobé poškozující zánětové reakce. Sanquis 2007;49:20-2.

35. Ernst E, Hammerschmidt DE, Bagge U. Leukocytes and the risk of ischemic diseases. J Am Med Asso 1987;257:2318-24.

36. Naldini A, Borelli E, Cesari S, Giomarelli P, Toscano M. In vitro cytosine production and t-cell proliferation in patiens under going cardiopulmonary bypass. Cytokine 1995; 7(2):165-70.

37. Lokaj J, John C. Ilja Iljič Mečnikov a Paul Ehrlich: laureáti Nobelovy ceny v r.1908 za práce o imunitě. Epidemiol Mikrobiol Imunol 2008;57(4):119-24.

38. Koenig W, Sund M, Frohlich M. C-reactive protein, sensitive marker of inflammation, predicts future risk of coronary heart disease in intially healthy modele-agedmen-results from the MONICA (Monitoring Trends and Determinants in Cardiovascular Disease) Augsburk kohort study 1984 to 1992. Circulation1999; I(99):237-42.

39. Habal P, Mandák J, Štětina M. Monitorace efektivity chirurgické léčby maligních pleurálních výpotků. Klin Onkol 2010;23(2):99-103.

40. Cassatella MA. The production of cytokines by polymorphonuclear neutrophils. Immunol Today 1995;16:21-6.

41. Habal P,Jankovicova K, Omran N, Krejsek J, Mandak J. The dynamics of selected local inflammatory markers to talc in the treatment of malignant pleural effusions. BiomedPap Med Fac Univ Palacky Olomouc Czech Repub 2013;157(4):311-5.

42. Jankovicova K, Kondelkova K, Habal P, Krejsek J, Mandak J. TLR2 in Pleural Fluid Is Modulated by Talc Particles during Pleurodesis. Clinical and Developmental Immunology 01/2012; 2012:158287. DOI:10.1155/2012/158287.

43. Wittebole X, Coyle SM, Kumer A. Expression of tomour necrosis factor receptor and Toll-like receptor 2 and 4 on peripherial blood leucocytes of human volunteers after endotoxin challenge: a comparison of flow cytometric light scatter and imunofluorescence gating. Clin Exp Immunol 2005;141:325-32.

44. Neustein SM. Reexpansion pulmonary edema. J Cardiotoracvasc Anesth 2007;1:887-91.

45. Kopman D, Berkowitz D, Boiselle P. Large-volume thoracocentesis and the risk of reexpansion pulmonary edema. An Torac Surg 2007;84:1656-61.

46. Her C, Mandy S. Acute respiratory distress syndrome of the contralateral lung after reexpansion pulmonary edema of a collapsed lung. J ClinAnesth 2004;16:244-50. 